\title{
Comparative Analysis of the Antioxidant and Free-Radical Scavenging Activities of Different Water-Soluble Extracts of Green, Black and Oolong Tea Samples
}

\author{
Jesús Tejero', Sara Gayoso', Irma Caro1, Damián Cordoba-Diaz², Javier Mateo³, \\ José E. Basterrechea ${ }^{1}$, Tomás Girbés ${ }^{1 *}$, Pilar Jiménez ${ }^{{ }^{*}}$ \\ ${ }^{1}$ Nutrición y Bromatología, Facultad de Medicina and CINAD (Centro de Investigación en Nutrición, \\ Alimentación y Dietética; Edificio Lucia-Parque Científico), Universidad de Valladolid, Valladolid, Spain \\ ${ }^{2}$ Farmacia y Tecnología Farmacéutica, Facultad de Farmacia and IUFI (Instituto Universitario de Farmacia \\ Industrial), Universidad Complutense de Madrid, Madrid, Spain \\ ${ }^{3}$ Higiene de los Alimentos y Tecnología, Facultad de Veterinaria, Universidad de León, León, Spain \\ Email: "girbes@bio.uva.es
}

Received 4 October 2014; revised 28 October 2014; accepted 14 November 2014

Copyright (C) 2014 by authors and Scientific Research Publishing Inc.

This work is licensed under the Creative Commons Attribution International License (CC BY).

http://creativecommons.org/licenses/by/4.0/

(c) (i) Open Access

\section{Abstract}

Extracts of 40 green, black or oolong high quality tea samples from China, Japan or India among others, have been prepared according to the manufacturer instructions and assayed for total polyphenols content using the Folin-Ciocalteu phenol reagent. In addition, the antioxidant activity was assessed by the CUPRAC method and the free-radical scavenging activity was determined using the antioxidant-promoting decay of the stable free-radical DPPH. Caffeine and the most important catechins were identified using RP-HPLC previously validated method. Results from this study suggest that teas, even though they content similar amounts of caffeine, differ considerably in polyphenolic content and therefore in antioxidant and free-radical scavenging activities, depending on the part of the plant used and the process applied to the material for the preparation of the final tea presentation. Correlations among Folin-Ciocalteau's reactivity of tea samples, the neocuproine reactivity, the DPPH decolourization and the HPLC analysis suggest that the antioxidant activity is due essentially to polyphenolic compounds present in teas, mainly EGCG. The best extraction method of tea powder was the one indicated by dealers. In general, the richest samples belong to green teas and the poorest samples belong to the black teas.

\footnotetext{
${ }^{*}$ Corresponding author.
} 


\section{Keywords}

\section{Tea, Polyphenols, Antioxidants, Free-Radical Scavenging}

\section{Introduction}

The benefits of tea polyphenols consumption have been well established. Tea polyphenols are a source of valuable phytochemical compounds whose consumption may affect health and be beneficial for pathologies, like cardiovascular disorders and cancer [1] [2]. Teas may be classified in at least three categories depending on the degree of fermentation. Unfermented teas are known as green teas, partially fermented teas are known as oolong teas and highly fermented teas are known as black teas. Independently of the fermentation degree, teas may be enriched with aroma from plants leading to a broad variety of teas featured by their flavour. From a health point of view green tea has been the most studied due to its richness in phenolic compounds known as phenolics. Among complex phenolics are flavanols and related compounds (Figure 1). The major flavanic polyphenols in green tea are (-)epicatechin-3-gallate (ECG), (-)epicatechin (EC), (-)epigallo-catechin (EGC) and (-)epigallocatechin-3-gallate (EGCG) [3]. The black tea also contains tearubigins and theaflavins [4]. Green tea polyphenol catechins (GTPs) are highly active molecules acting as antioxidant [2], pro-oxidant [5], anti-inflammatory [6] and anti-cancer [7] agents. EGCG is the most widely studied catechin [1]. Among the standardized preparations enriched in green tea polyphenols is Polyphenon ${ }^{\circledR}$ which has been used in studies into inflammation-related colon carcinogenesis in mice [6] and in studies of catechin pharmacokinetics in healthy human beings [3] [5]. The combination of EGCG and sulindac significantly enhanced apoptosis in rat colon, reducing the aberrant crypt foci [8]. Despite these positive effects, administration of very large doses of concentrated green tea extracts has been shown to trigger certain adverse effects that rise concerns from a food safety point of view [9]-[11]. The aim of the present research was to compare the total phenolic content and the antioxidant and free-radical scavenging activities of a number of samples of different green, oolong and black teas from Asia and Africa prepared as water extracts as indicated by the dealers.<smiles>O=C(O[C@H]1Cc2c(O)cc(O)cc2O[C@H]1c1ccc(O)c(O)c1)c1cc(O)c(O)c(O)c1</smiles>

(-) epicatechin-3-gallate<smiles>Oc1cc(O)c2c(c1)O[C@H](c1cc(O)c(O)c(O)c1)[C@H](O)C2</smiles>

$(-)$ epigallocatechin<smiles>Oc1cc(O)c2c(c1)O[C@H](c1ccc(O)c(O)c1)[C@H](O)C2</smiles>

(-) epicatechin<smiles>O=C(O[C@H]1Cc2c(O)cc(O)cc2O[C@@H]1c1cc(O)c(O)c(O)c1)c1cc(O)c(O)c(O)c1</smiles>

(-) epigallo-catechin-3-gallate

Figure 1. Green tea major catechins. 


\section{Materials and Methods}

\subsection{Materials}

All common reagents were of the highest grade commercially available. 2,2-diphenyl-1-picrylhydrazyl (DPPH), Folin-Ciocalteau's phenol reagent (FC), $\mathrm{FeCl}_{3}$ and neocuproine were purchased to Sigma-Aldrich Química S.A. (Tres Cantos, Spain). Tea samples were purchased from different commercial sources as indicated in the tables. Preparation of the water extracts was performed as indicated by the tea distributor.

\subsection{Tea Samples and Preparations of Teas}

1 (3 years Kukicha, Japan, green); 2 (Sencha, Japan, green); 3 (Kukicha, Japan, green); 4 (3 years Hojicha, Japan, green); 5 (Bancha, Japan, green); 6 (Bancha leaf, Japan, green); 7 (second Matcha, Japan, green); 8 (Gyokuro, Japan, green); 9 (first Matcha, Japan, green); 10 (Wild Green, Japan, green); 11 (Special Gunpowder, China, green); 12 (Bi Luo Chung, China, green); 13 (Black, Ethiopia, black); 14 (Long Jing, China, green); 15 (Tai Ping China, green); 16 (Chun Mee, China, green); 17 (Jade Rings, China, green); 18 (Mo Li Feng Yan, China, green); 19 (Long Jing Dragon Well, China, green); 20 (Orange Pekoe, Portugal, black); 21 (Yunnan Supreme, China, black); 22 (Keemun, China, black); 23 (LapsangSouchong, China, black); 24 (Wen Shan BaoZhong, China, oolong); 25 (Ba Xian, China, oolong); 26 (Tung Ting, China, oolong); 27 (Da Hong Pao, China, oolong); 28 (Ro Gui (Cassia), China, oolong); 29 (BaiHaooolong, China, oolong); 30 (Ding Dong, China, oolong); 31 (Yabao (Silver Pu-er bud raw), China, Pu-er); 32 (Old Pu-er, China, Pu-er); 33 (block Pu-er, China, Pu-er); 34 (FTGFOP1, India, black); 35 (SFTGFOP, India, black); 36 (First Flush, India, black); 37 (Second Flush, India, black); 38 (First Flush, India, black); 39 (Black, Tanzania, black); 40 (Black, Madagascar, black). For the preparation of water extracts $1 \mathrm{~g}$ of the corresponding tea samples were mixed with $50 \mathrm{~mL}$ of hot water according to the manufacturer's instructions. The resulting water extract was used immediately for the assays.

\subsection{Total Phenols Content}

Total phenolic compounds present in tea extracts were determined with the Folin-Ciocalteau's phenol reagent for phenolics [12]. Reaction mixtures of $1.5 \mathrm{~mL}$ contained $0.6 \mathrm{~mL}$ of sodium carbonate saturated solution, 0.2 $\mathrm{mL}$ of $\mathrm{FC}$ and $0.1 \mathrm{~mL}$ of sample. The resulting mixtures were incubated for $10 \mathrm{~min}$ at $50^{\circ} \mathrm{C}$ and cooled prior the measurement of the absorbance at a wavelength of $760 \mathrm{~nm}$. Gallic acid was used as standard for calibration. The values obtained in the reaction of the samples with the FC were expressed as mg of gallic acid equivalents (GAE) per gram (wet weight) of plant material.

\subsection{CUPRAC Assay}

Antioxidant activity was determined by the CUPRAC assay as reported elsewhere [13]. Reaction mixtures containing $0.02 \mathrm{~mL}$ of sample, $1 \mathrm{~mL}$ of $10 \mathrm{mM} \mathrm{CuCl}, 1 \mathrm{~mL}$ of $7.5 \mathrm{mM}$ neocuproine in ethanol and $1 \mathrm{~mL}$ of $1 \mathrm{M}$ ammonium acetate ( $\mathrm{pH} 7.0$ ) were prepared and kept for $60 \mathrm{~min}$ to allow colour development and after were read at $\mathrm{A}_{450}$. Gallic acid was used as standard for calibration. The results were expressed as gallic acid equivalents (GAE) per gram (wet weight) of plant material.

\subsection{DPPH Assay}

The capacity to scavenge free radicals was assessed by DPPH colour decay after 10 min of incubation [14]. Reaction mixtures containing $0.03 \mathrm{~mL}$ of sample and $2.9 \mathrm{~mL}$ of DPPH dissolved in methanol were kept in the dark for colour development and the reduction in colour was determined by measuring the absorbance signal at a wavelength of $515 \mathrm{~nm}$. Trolox ${ }^{\circledR}$ was used as standard and results were expressed as Trolox ${ }^{\circledR}$ equivalents per gram (wet weight) of plant material.

\subsection{Determination of Polyphenols}

The contents of polyphenols and caffeine in the tea varieties were analysed in duplicate using RP-HPLC with UV detector. Polyphenols and caffeine were first extracted in hot water as indicated in the envelop of the tea and the aqueous extract was immediately filtered through cotton-wool. $8 \mathrm{~mL}$ of filtrate were mixed with $2 \mathrm{~mL}$ of 
methanol and the mix was filtered under vacuum through a $0.45 \mu \mathrm{m}$ membrane. A Waters 2690 Alliance (Waters, Milford, MA, USA) separation module equipped with a Supelcosil LC-18 analytical (5 $\mu \mathrm{m}, 150 \mathrm{~mm} \times 4.6$ mm I.D.; Bellefonte, PA, USA), protected by a C18 $(10 \mu \mathrm{m}, 30 \mathrm{~mm} \times 4.6 \mathrm{~mm})$ pre-column guard cartridge, and coupled with a Waters 996 Photodiode Array Detector (Waters) were used in the analysis. The separation of compounds in the column and detection were carried out at $20^{\circ} \mathrm{C}$. Compounds were eluted undergradient in water ( $0.1 \%$ formic acid)/methanol ( $0.1 \%$ formic acid) in which the concentration of water varied as follows: 0 min, $80 \%$; from 0 to $15 \mathrm{~min}$, decreased to $50 \%$; from 15 to $25 \mathrm{~min}, 50 \%$. The flow rate was $1 \mathrm{~mL} / \mathrm{min}$, the detection of compounds was achieved at $280 \mathrm{~nm}$, and injection volume was $20 \mu \mathrm{L}$. Quantification was achieved using Polyphenon 60 as standard and confirmed with either caffeine or catechins alone as standard (Sigma Chemical Co., St. Louis, MO, USA).

\section{Results and Discussion}

The administration of large oral doses of a concentrated green tea known as Polyphenon 60 increases the toxicity of the ribosome-inactivating protein ebulin $\mathrm{f}$ due to a synergic proapoptopic action of tea catechins with ebulin $\mathrm{f}$ [11]. During these studies, we found different effects of tea depending on the source. In order to gain insights on these differences we analysed forty tea samples from Asia, Europe and Africa countries obtained from different manufacturers for total phenolic content, antioxidant and anti-free-radical scavenging activities. They belong to green, oolong, Pu-er and black categories.

Total phenolics were determined with the Folin-Ciocalteau's reagent for phenols. The reaction is a typical electron transfer assay based on the oxidation/reduction reaction of samples [15] [16]. FC reacts also with non-phenolic compounds like ascorbic acid, cysteine, fructose, sucrose, uric acid, and xanthine among a number of organic substances and iron sulphate, sodium phosphate and tin chloride among the inorganic ones [15]. Therefore, our measures may account not only for phenolics but also for undetermined amounts of other water-soluble reductive substances present in the extracts. Our results indicate clearly that the total content of phenolics was dependent on the type of tea. In general, the richest samples belong to green teas (Table 1 and Table 2). The poorest samples belong to the black teas. Oolong teas showed intermediate values. Noteworthy, the richness in phenolics was very different among the same tea type depending on the part of the plant used and the process applied to the material for the preparation of the final tea presentation. Water extraction of tea samples with hot water was highly dependent on the form of industrial preparation of tea. As expected, phenolic extraction of tea powder was better than stalks and leaves for the times indicated by the dealers.

The antioxidant activity of tea samples was determined with neocuproine (2,9-dimethyl-1,10-phenantroline) in the assay known as CUPRAC. In the original procedure it was reported that $\mathrm{Cu}^{2+}$ is reduced by the sample and the resulting $\mathrm{Cu}^{+}$forms a complex with two molecules of neocuproine that absorbs at $450 \mathrm{~nm}$ [17]. As shown in Table 1 and Table 2, the antioxidant activities of teas were dependent on the tea type.

The free-radical scavenging activity of teas was studied using the decolourization assay of the stable free-radical 2,2-diphenyl-1-picrylhydrazyl known as DPPH [15] [18]. The chemical process is an electrontransfer reaction in which the deep purple colour of DPPH is time-dependent decoloured by the biological sample to be tested by following the absorbance at $515 \mathrm{~nm}$ with a colorimeter [15] [19]. As shown also in Table 1 and Table 2, tea-dependent decolourization of DPPH run in parallel to the content in polyphenols and the antioxidant activity of the samples. In this line, we analysed the correlation between the values obtained in the different procedures to ascertain whether quantitative relationships exists between the content in phenols and the antioxidant and free-radical scavenging activities.

The water extracts of teas were prepared as indicated by the manufacturers, which differ among teas. Most of them recommend 2 - 3 min of contact between tea sample and hot water. To ascertain whether longer times could improve extraction, we selected two teas samples of each tea type and extracted phenolics with hot water after 5 and 10 min of the addition of boiling water. As Figure 2 shows, extraction for 10 min led to an increase of material that reacted with FC in the range of $14 \%$ to $28 \%$. In the case of reaction with DPPH the differences were much higher reaching $56 \%$ in the Pu-er tea. At room temperature, the temperature of water used for the extractions decrease from $100^{\circ} \mathrm{C}$ to $70^{\circ} \mathrm{C}$ in $2 \mathrm{~min}$ and to $50^{\circ} \mathrm{C}$ in $10 \mathrm{~min}$, independently of the recipient used for extraction (glass or steel vessel like that used in cafeteria). For most teas with high content of polyphenolic material, 2 - 3 min of extraction with hot water ensures a good recovery of polyphenols with a minimum of aroma loss. 
Table 1. Total phenolics, antioxidant and free radical scavenging activities of green tea extracts (GAE, gallic acid equivalents; TE, Trolox equivalents; SD, standard deviation).

\begin{tabular}{ccccccc}
\hline \multirow{2}{*}{$\begin{array}{c}\text { Tea } \\
\text { Code }\end{array}$} & Total phenols content & \multicolumn{3}{c}{ Antioxidant activity } & \multicolumn{2}{c}{ Free-radical scavenging activity } \\
\cline { 2 - 7 } & GAE (mg)/Wet weight of tea (g) & SD & GAE (mg)/Wet weight of tea (g) & SD & TE (mg)/Wet weight of tea (g) & SD \\
\hline 7 & 149.55 & 1.54 & 62.40 & 4.14 & 218.46 & 1.06 \\
2 & 146.49 & 2.92 & 45.73 & 0.80 & 203.24 & 4.96 \\
9 & 142.70 & 2.85 & 53.00 & 2.53 & 193.46 & 1.27 \\
8 & 121.08 & 3.51 & 35.23 & 0.96 & 116.60 & 11.01 \\
19 & 97.66 & 3.13 & 30.93 & 0.59 & 105.80 & 2.56 \\
17 & 93.33 & 0.41 & 29.53 & 0.16 & 94.86 & 1.09 \\
16 & 78.20 & 0.68 & 30.27 & 2.86 & 128.79 & 7.10 \\
11 & 54.59 & 2.31 & 19.70 & 0.41 & 72.42 & 4.72 \\
12 & 53.78 & 2.31 & 21.57 & 2.82 & 74.36 & 1.27 \\
15 & 52.16 & 0.97 & 19.03 & 3.11 & 76.71 & 6.57 \\
6 & 46.94 & 0.68 & 20.17 & 1.55 & 68.22 & 6.19 \\
3 & 46.76 & 0.27 & 13.93 & 0.21 & 51.18 & 1.24 \\
14 & 38.83 & 0.83 & 15.60 & 1.07 & 64.67 & 17.60 \\
5 & 36.76 & 1.24 & 11.27 & 1.00 & 50.42 & 2.16 \\
10 & 33.78 & 1.62 & 4.90 & 0.74 & 34.20 & 4.79 \\
18 & 22.07 & 2.45 & 4.53 & 0.89 & 25.00 & 0.89 \\
1 & 19.01 & 1.36 & 5.67 & 0.26 & 16.08 & 2.81 \\
4 & 16.58 & 0.83 & & & 1.01 & 1.82 \\
\hline
\end{tabular}

Table 2. Total phenolics, antioxidant and free radical scavenging activities of black tea extracts (GAE, gallic acid equivalents; TE, Trolox equivalents; SD, standard deviation).

\begin{tabular}{|c|c|c|c|c|c|c|}
\hline \multirow{2}{*}{$\begin{array}{c}\text { Tea } \\
\text { Code }\end{array}$} & \multicolumn{2}{|l|}{ Total phenols content } & \multicolumn{2}{|l|}{ Antioxidant activity } & \multicolumn{2}{|c|}{ Free-radical scavenging activity } \\
\hline & GAE (mg)/Wet weight of tea (g) & SD & GAE (mg)/Wet weight of tea (g) & $\mathrm{SD}$ & TE (mg)/Wet weight of tea (g) & SD \\
\hline 37 & 59.64 & 0.95 & 18.83 & 0.43 & 68.33 & 1.31 \\
\hline 36 & 58.47 & 0.95 & 18.07 & 0.26 & 62.47 & 2.36 \\
\hline 39 & 55.77 & 1.09 & 16.93 & 0.21 & 52.05 & 1.08 \\
\hline 38 & 51.62 & 0.54 & 15.97 & 0.16 & 49.05 & 1.31 \\
\hline 21 & 48.38 & 1.50 & 13.10 & 0.27 & 55.12 & 3.01 \\
\hline 40 & 46.31 & 0.68 & 15.33 & 0.16 & 36.20 & 1.78 \\
\hline 35 & 45.86 & 1.02 & 14.87 & 0.16 & 24.77 & 1.50 \\
\hline 34 & 44.95 & 0.56 & 14.33 & 0.16 & 21.63 & 1.50 \\
\hline 13 & 41.44 & 1.09 & 13.63 & 0.16 & 21.92 & 0.86 \\
\hline 22 & 35.14 & 1.77 & 9.37 & 0.36 & 17.61 & 4.08 \\
\hline 20 & 24.86 & 2.74 & 4.83 & 1.13 & 31.27 & 1.98 \\
\hline 23 & 14.23 & 1.09 & 3.27 & 0.42 & 9.62 & 2.36 \\
\hline 25 & 50.45 & 0.95 & 17.00 & 0.64 & 73.23 & 1.54 \\
\hline 28 & 49.46 & 1.89 & 12.50 & 0.21 & 45.56 & 2.20 \\
\hline 27 & 38.38 & 1.24 & 10.60 & 0.47 & 25.45 & 1.73 \\
\hline 24 & 32.70 & 0.81 & 8.13 & 0.31 & 13.47 & 1.73 \\
\hline 30 & 24.50 & 0.95 & 7.10 & 0.41 & 12.20 & 1.08 \\
\hline 29 & 12.16 & 0.81 & 5.43 & 0.26 & 9.63 & 0.65 \\
\hline 26 & 6.67 & 0.56 & 1.60 & 0.27 & 6.20 & 0.89 \\
\hline 33 & 29.19 & 0.97 & 11.83 & 0.33 & 14.20 & 0.86 \\
\hline 32 & 10.90 & 0.68 & 2.47 & 0.49 & 7.21 & 0.65 \\
\hline 31 & 5.59 & 0.41 & 0.47 & 0.16 & 3.06 & 1.96 \\
\hline
\end{tabular}

In order to establish a quantitative relationship between the polyphenols content and the antioxidant and free radical scavenging activities of the different tea samples we carried on a study of correlation. As it is shown in 

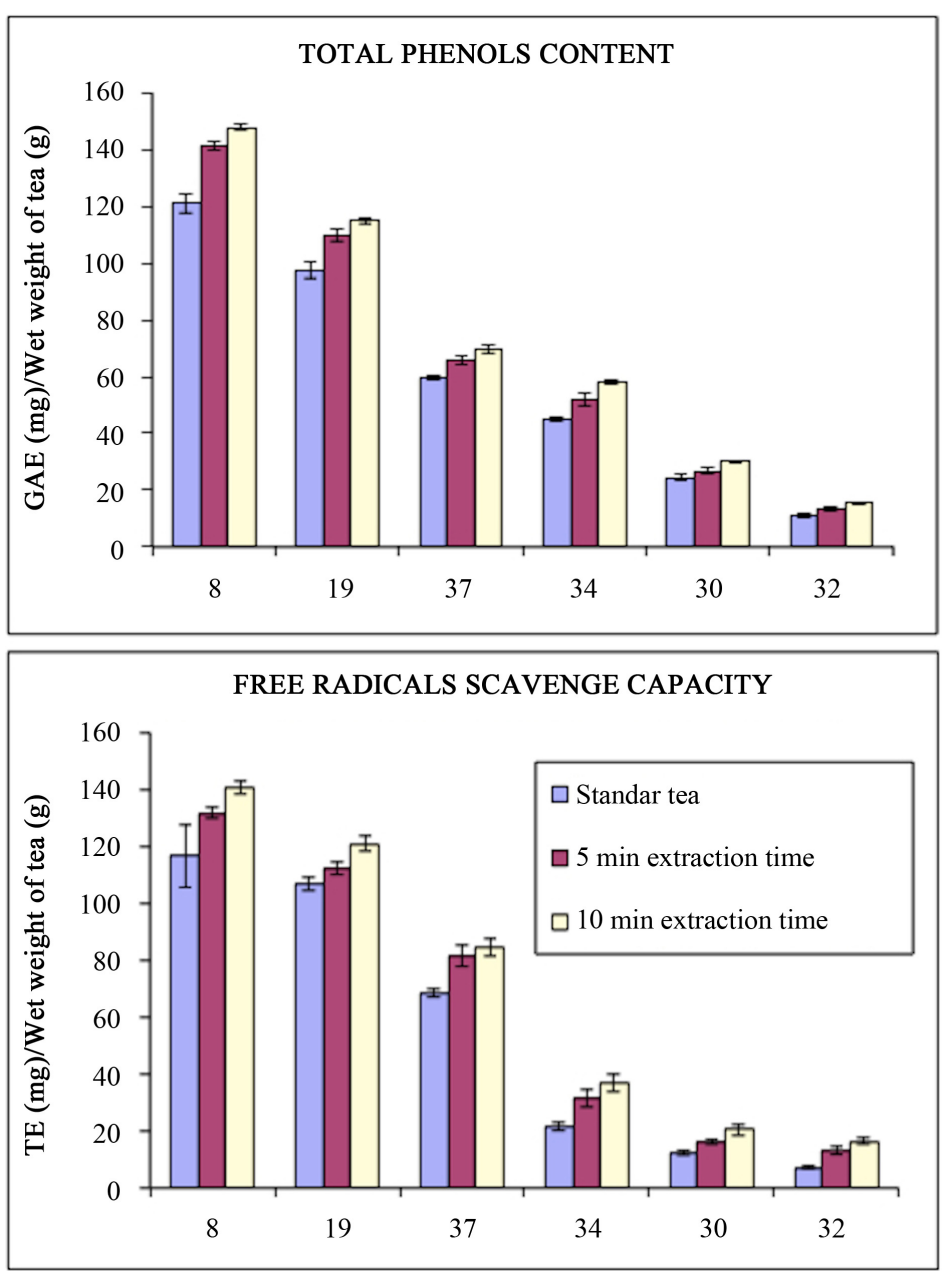

Figure 2. Influence of extraction time on total phenolics content and free radical scavenging activities of some selected teas.

Figure 3, the match of reactivity of teas water extracts with FC, with the values of the CUPRAC assay led to a straight line corresponding to the equation $\mathrm{y}=0.3628 \mathrm{x}-1.7827$ with a $\mathrm{R}^{2}$ value of 0.9528 . The match of FC assay with the values of the DPPH decolourization assay gave also a straight line corresponding to the equation $\mathrm{y}=1.3857 \mathrm{x}-13.979$ with $\mathrm{R}^{2}$ value of 0.9068 . These results indicated that the antioxidant capacity of the water extracts of tea is due to a great degree to the polyphenols content. On the other hand, we found also a good correlation between the antioxidant activity assessed by the CUPRAC procedure and the free radical scavenging activity assessed as loss of colour of DPPH with the equation $y=3.7872 x-6.632$ and a $\mathrm{R}^{2}$ value of 0.9358 .

We further analysed the different tea samples by HPLC and compared with the catechins content of Polyphenon 60. As shown in Figure 4, Polyphenon ${ }^{\circledR} 60$ contents the four major catechins plus a significant content of caffeine. The most abundant catechin in the Polyphenon ${ }^{\circledR} 60$ we used was EGCG, followed by EGC, ECG and ECC. The HPLC analysis of the tea samples indicated that the content of catechins run in parallel with the result obtained in the reaction of water extracts with FC; the major reaction the higher content in catechins is. It is noteworthy that some tea samples were rich in caffeine and very poor in catechins as determined by reaction with the phenol reagent and by HPLC. Such tea samples showed a very low reaction with the phenol reagent.

Daily tea drinking is considered currently as a healthy practice due to the antioxidant substances therein contained especially polyphenols [1] [2] [20]-[23]. Such compounds positively affect many biological functions. Therefore, if its consumption is aimed to improve the antioxidant state of the consumer the content in polyphenols should be taken into account. Nonetheless, tea is appreciated not only by antioxidant effects but also by its flavour and taste. 


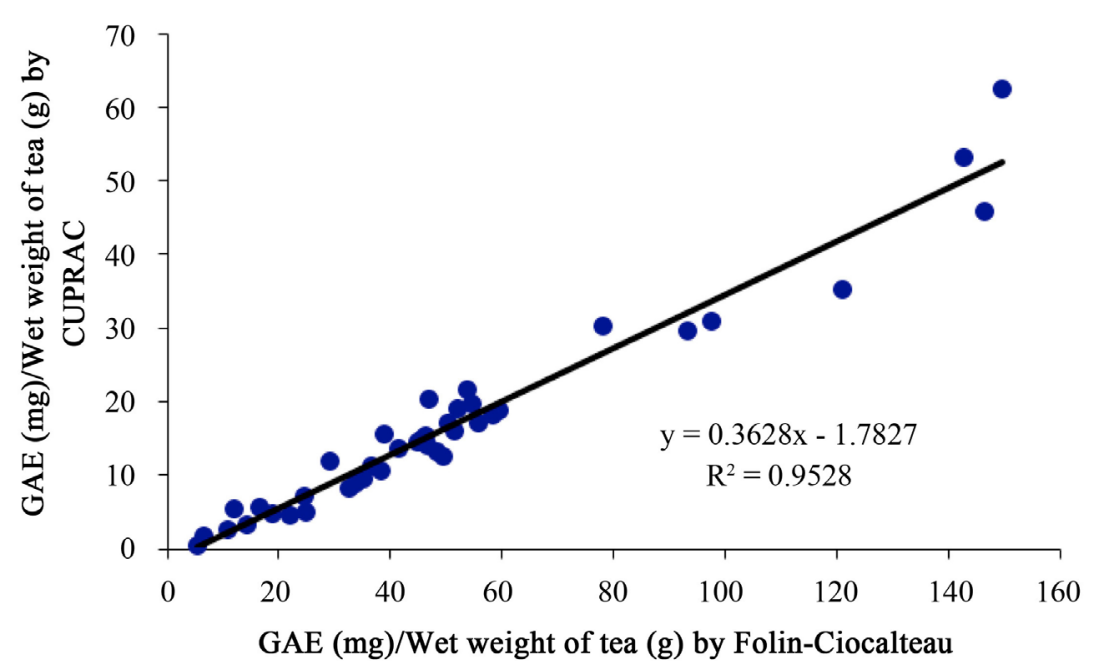

(a)



(b)

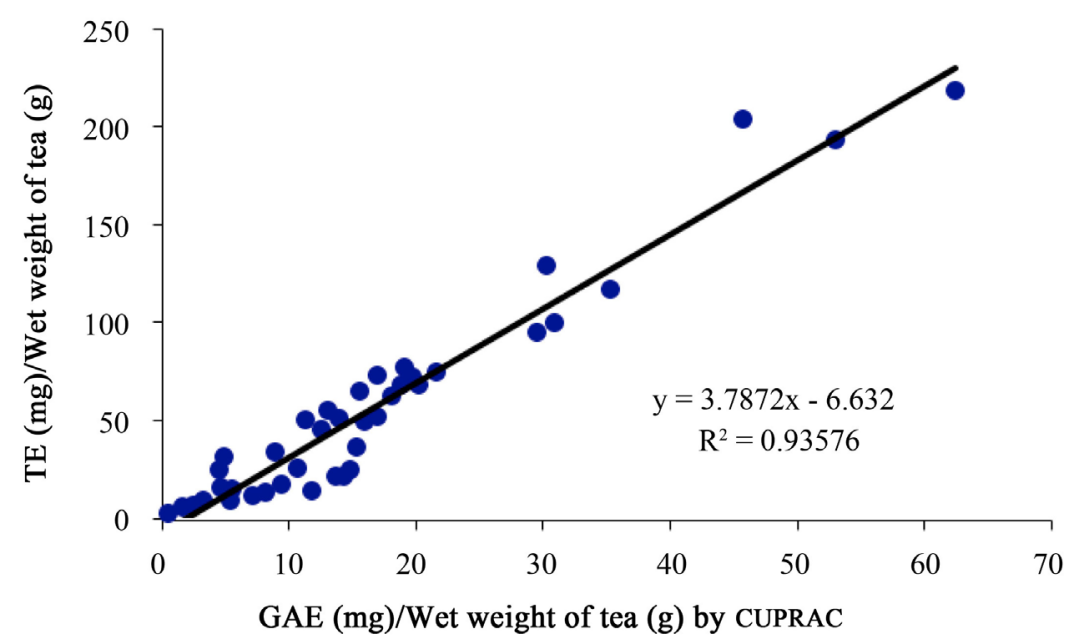

(c)

Figure 3. Correlation plots between the polyphenols content and antioxidant and free radical scavenging activities of the different tea samples. 


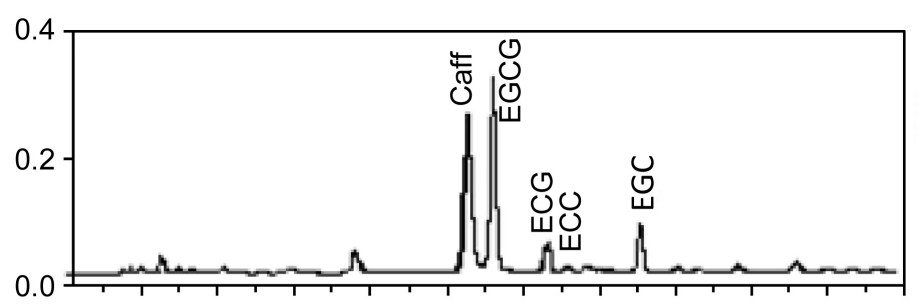

(a)

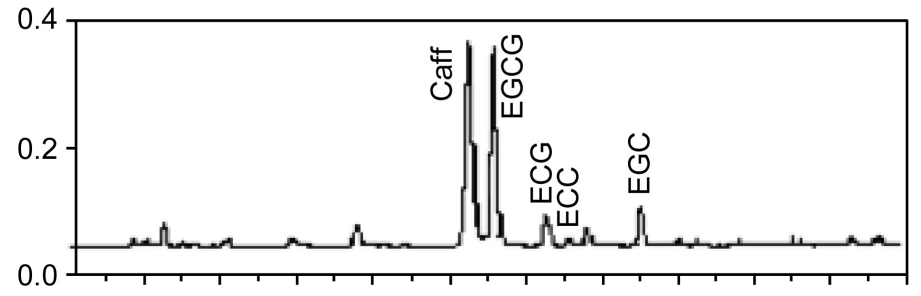

(b)

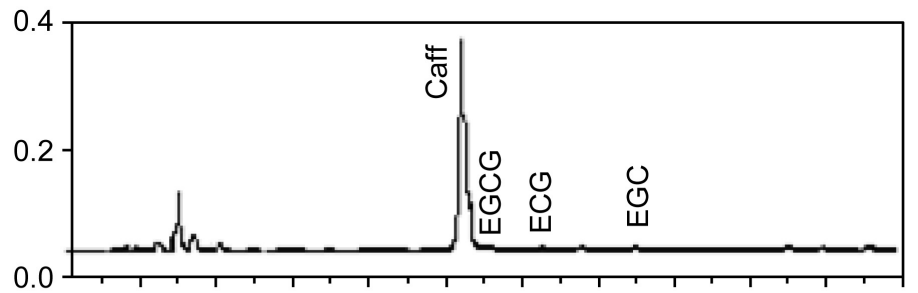

(c)

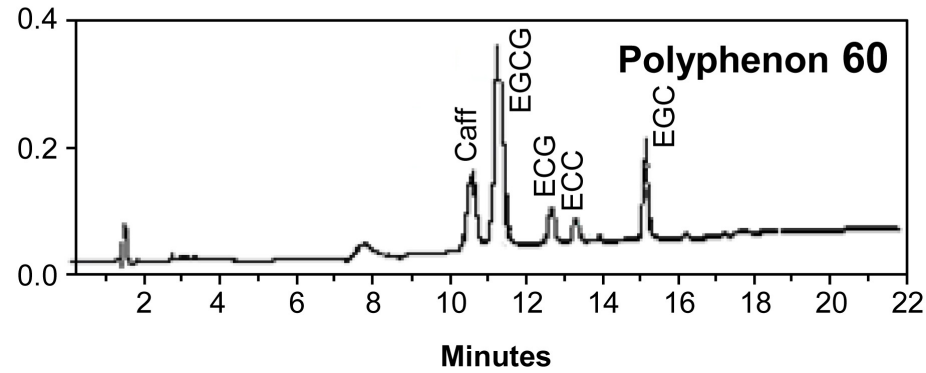

Figure 4. Chromatogram obtained from tea samples ((a): Sencha; (b): Mat cha1 ${ }^{\mathrm{a}}$; (c): Da Hong Pao) and Polyphenon 60 (Caff: Caffeine; EGCG: Epigallo-catechin-3-gallate; ECG: Epicatechin-3-gallate; ECC: Epicatechin; EGC: Epigallocatechin).

\section{Conclusion}

Our results indicate that teas, even though they content similar amounts of caffeine, differ considerably in polyphenolic content and therefore in antioxidant and free-radical scavenging activities. Antioxidant and free radical scavenging quality was dependent on the industrial processing of tea samples. In general, the less processed and fermented teas were the richest ones. Optimal extractions of phenolics from tea samples were observed following the indications of tea dealers. The form of tea presentation, powder, stalks or leaves, had also a deep influence in the extraction of antioxidants. Correlations between Folin-Ciocalteau's reactivity of tea sample, the neocuproine reactivity and DPPH decolourization suggest that the antioxidant activity is due essentially to polyphenolic compounds present in teas, mainly EGCG.

\section{Acknowledgements}

The present research was supported by grants from the Junta de Castilla y León (Grupo de Investigación de Excelencia GR106) and UVa-GIR to T.G. 


\section{References}

[1] Kanwar, J., Taskeen, M., Mohammad, I., Huo, C., Chan, T.H. and Dou, Q.P. (2012) Recent Advances on Tea Polyphenols. Frontiers in Bioscience (Elite Edition), 4, 111-131. http://dx.doi.org/10.2741/363

[2] Yang, C.S., Wang, X., Lu, G. and Picinich, S.C. (2009) Cancer Prevention by Tea: Animal Studies, Molecular Mechanisms and Human Relevance. Nature Reviews Cancer, 9, 429-439. http://dx.doi.org/10.1038/nrc2641

[3] Johnson, J.J., Bailey, H.H. and Mukhtar, H. (2010) Green Tea Polyphenols for Prostate Cancer Chemoprevention: A Translational Perspective. Phytomedicine, 17, 3-13. http://dx.doi.org/10.1016/j.phymed.2009.09.011

[4] Sang, S., Lambert, J.D., Ho, C.T. and Yang, C.S. (2011) The Chemistry and Biotransformation Of Tea Constituents. Pharmacology Research, 64, 87-99. http://dx.doi.org/10.1016/j.phrs.2011.02.007

[5] Hou, Z., Sang, S., You, H., Lee, M.J., Hong, J., Chin, K.V. and Yang, C.S. (2005) Mechanism of Action of (-)-Epigallocatechin-3-Gallate: Auto-Oxidation Dependent Inactivation of Epidermal Growth Factor Receptor and Direct Effects on Growth Inhibition in Human Esophageal Cancer KYSE 150 Cells. Cancer Research, 65, 8049-8056.

[6] Shirakami, Y., Shimizu, M., Tsurumi, H., Hara, Y., Tanaka, T. and Moriwaki, H. (2008) EGCG and Polyphenon 60 Attenuate Inflammation-Related Mouse Colon Carcinogenesis Induced by AOM plus DDS. Molecular Medicine Reports, 1, 355-361. http://dx.doi.org/10.3892/mmr.1.3.355

[7] Shimizu, M., Adachi, S., Masuda, M., Kozawa, O. and Moriwaki, H. (2011) Cancer Chemoprevention with Green Tea Catechins by Targeting Receptor Tyrosine Kinases. Molecular Nutrition and Food Research, 55, 832-843. http://dx.doi.org/10.1002/mnfr.201000622

[8] Ohishi, T., Kishimoto, Y., Miura, N., Shiota, G., Kohri, T., Hara, Y., Hasegawa, J. and Isemura, M. (2002) Synergistic Effects of (-)-Epigallocatechin Gallate with Sulindac Against Colon Carcinogenesis of Rats Treated with Azoxymethane. Cancer Letters, 177, 49-56. http://dx.doi.org/10.1016/S0304-3835(01)00767-4

[9] Schönthal, A.H. (2011) Adverse Effects of Concentrated Green Tea Extracts. Molecular Nutrition and Food Research, 55, 874-885. http://dx.doi.org/10.1002/mnfr.201000644

[10] Lambert, J.D., Kennett, M.J., Sang, S., Reuhl, K.R., Ju, J. and Yang, C.S. (2010) Hepatotoxicity of High Oral Dose (-)-Epigallocatechin-3-Gallate in Mice. Food and Chemical Toxicology, 48, 409-416. http://dx.doi.org/10.1016/j.fct.2009.10.030

[11] Jimenez, P., Cabrero, P., Tejero, J., Gayoso, M.J., Garrosa, M., Córdoba-Díaz, D. and Girbes, T. (2014) Concentrated Extract of Green Tea Polyphenols Enhances the Toxicity of the Elderberry Lectin Nigrin b to Mice. Food and Nutrition Sciences, 5, 466-471. http://dx.doi.org/10.4236/fns.2014.55055

[12] Heleno, S.A., Barros, L., Martins, A., Queiroz, M.J., Santos-Buelga, C. and Ferreira, I.C. (2012) Phenolic, Polysaccharidic, and Lipidic Fractions of Mushrooms from Northeastern Portugal: Chemical Compounds with Antioxidant Properties. Journal of Agricultural and Food Chemistry, 60, 4634-4640. http://dx.doi.org/10.1021/jf300739m

[13] Jimenez, P., Cabrero, P., Basterrechea, J.E., Tejero, J., Cordoba-Diaz, D., Cordoba-Diaz, M. and Girbes, T. (2014) Effects of Short-Term Heating on Total Polyphenols, Anthocyanins, Antioxidant Activity and Lectins of Different Parts of Dwarf Elder (Sambucus ebulus L.). Plant Foods for Human Nutrition, 69, 168-174. http://dx.doi.org/10.1007/s11130-014-0417-x

[14] Reis, F.S., Barros, L., Martins, A. and Ferreira, I.C.F.R. (2012) Chemical Composition and Nutritional Value of the Most Widely Appreciated Cultivated Mushrooms: An Inter-Species Comparative Study. Food and Chemical Toxicology, 50, 191-197. http://dx.doi.org/10.1016/j.fct.2011.10.056

[15] Prior, R.L., Wu, X. and Schaich, K. (2005) Standardized Methods for the Determination of Antioxidant Capacity and Phenolics in Foods and Dietary Supplements. Journal of Agricultural and Food Chemistry, 53, 4290-4302 http://dx.doi.org/10.1021/jf0502698

[16] Huang, D., Ou, B. and Prior, R. (2005) The Chemistry Behind Capacity Assays. Journal of Agricultural and Food Chemistry, 53, 1841-1856. http://dx.doi.org/10.1021/jf030723c

[17] Apak, R., Güçlü, K., Ozyürek, M. and Karademir, S.E. (2004) Novel Total Antioxidant Capacity Index for Dietary Polyphenols and Vitamins C and E, Using Their Cupric Ion Reducing Capability in the Presence of Neocuproine: CUPRAC Method. Journal of Agricultural and Food Chemistry, 52, 7970-7981. http://dx.doi.org/10.1021/jf048741x

[18] Bondet, V., Brand-Williams, W. and Berset, C. (1997) Kinetics and Mechanisms of Antioxidant Activity Using the DPPH Free Radical Method. LWT- Food Science and Technology, 30, 609-615. http://dx.doi.org/10.1006/fstl.1997.0240

[19] Sanchez Moreno, C., Larrauri, J.A. and Saura-Calixto, F. (1998) A Procedure to Measure the Antiradical Efficiency of Polyphenols. Journal of the Science of Food and Agriculture, 76, 270-276. http://dx.doi.org/10.1002/(SICI)1097-0010(199802)76:2\%3C270::AID-JSFA945\%3E3.3.CO;2-0

[20] Mousavi, A., Vafa, M., Neyestani, T., Khamseh, M. and Hoseini, F. (2013) The Effects of Green Tea Consumption on 
Metabolic and Anthropometric Indices in Patients with Type 2 Diabetes. Journal of Research in Medical Sciences, 18, 1080-1086.

[21] Frank, J., George, T.W., Lodge, J.K., Rodriguez-Mateos, A.M., Spencer, J.P.E., Minihane, A.M. and Rimbach, G. (2009) Daily Consumption of an Aqueous Green Tea Extract Supplement Does Not Impair Liver Function or Alter Cardiovascular Disease Risk Biomarkers in Healthy Men. The Journal of Nutrition, 139, 58-62. http://dx.doi.org/10.3945/jn.108.096412

[22] Gao,M., Ma, W., Chen, X.B., Chang, Z.W., Zhang, X.D. and Zhang, M.Z. (2013) Meta-Analysis of Green Tea Drinking and the Prevalence of Gynecological Tumors in Women. Asia Pacific Journal of Public Health, 25, 43S-48S. http://dx.doi.org/10.1177/1010539513493313

[23] Danesi, F., Di Nunzio, M., Boschetti, E. and Bordoni, A. (2009) Green Tea Extract Selectively Activates Peroxisome Proliferator-Activated Receptor Beta/Delta in Cultured Cardiomyocytes. British Journal of Nutrition, 101, 1736-1739. http://dx.doi.org/10.1017/S0007114508145871 
Scientific Research Publishing (SCIRP) is one of the largest Open Access journal publishers. It is currently publishing more than 200 open access, online, peer-reviewed journals covering a wide range of academic disciplines. SCIRP serves the worldwide academic communities and contributes to the progress and application of science with its publication.

Other selected journals from SCIRP are listed as below. Submit your manuscript to us via either submit@scirp.org or Online Submission Portal.
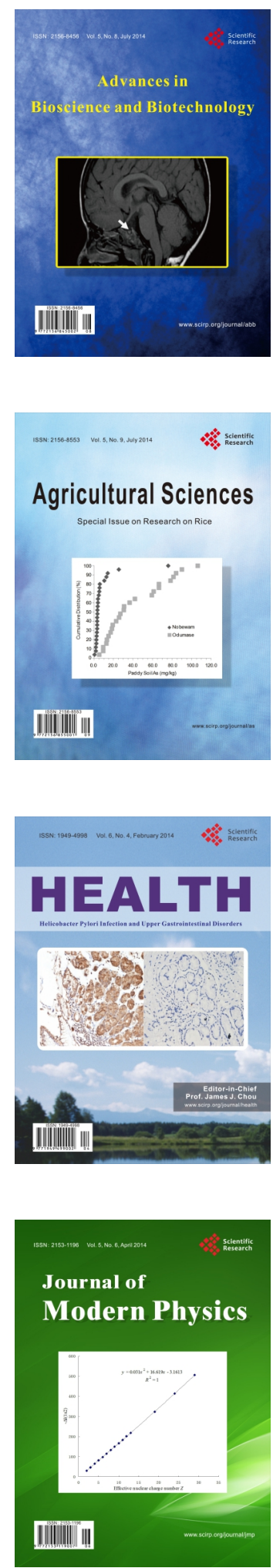
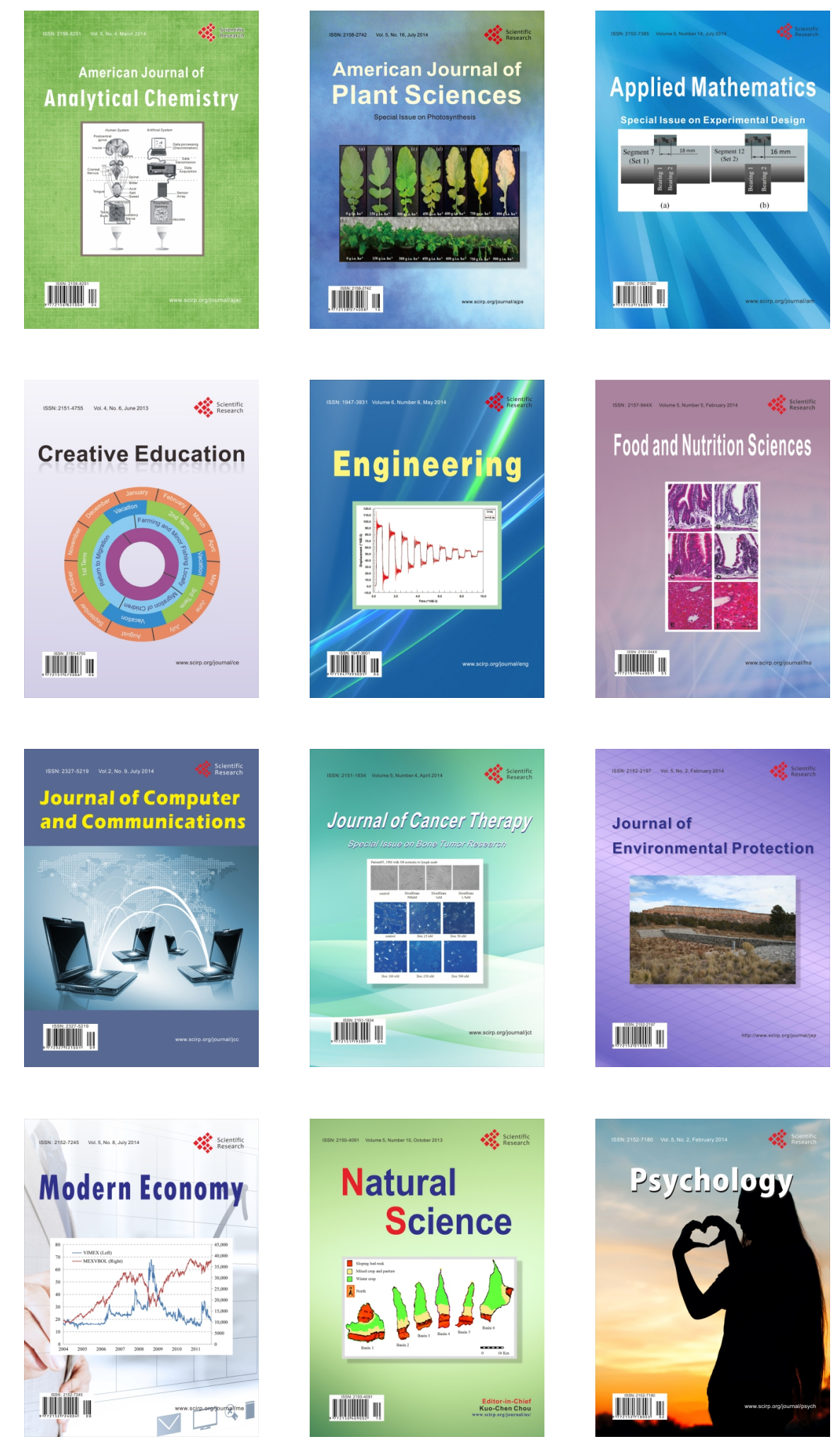